\title{
Correction to: Pre-clinical evaluation of Minnelide as a therapy for acute myeloid leukemia
}

Bhuwan Giri, Vineet K. Gupta, Brianna Yaffe, Shrey Modi, Pooja Roy, Vrishketan Sethi, Shweta P. Lavania, Selwyn M. Vickers, Vikas Dudeja, Sulagna Banerjee, Justin Watts and Ashok Saluja*

\section{Correction to: J Transl Med (2019) 17:163}

https://doi.org/10.1186/s12967-019-1901-8

Following publication of the original article [1], the authors found an error in Fig. 3. The middle panel of Fig. 3a was inadvertently duplicated.

In this Correction the incorrect and corrected version of Fig. 3 are shown. 
Originally Fig. 3 was published as:

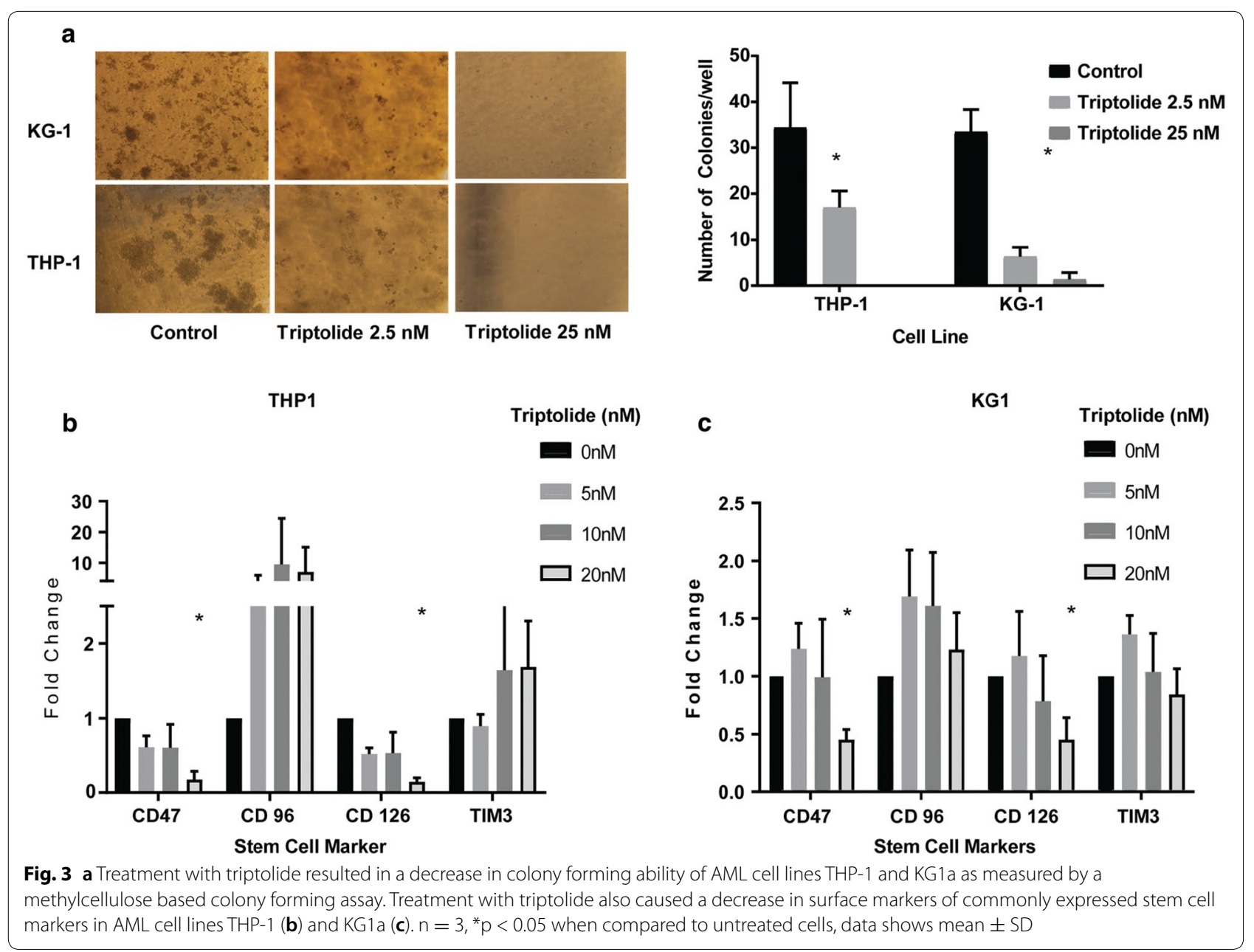


The corrected version of Fig. 3:

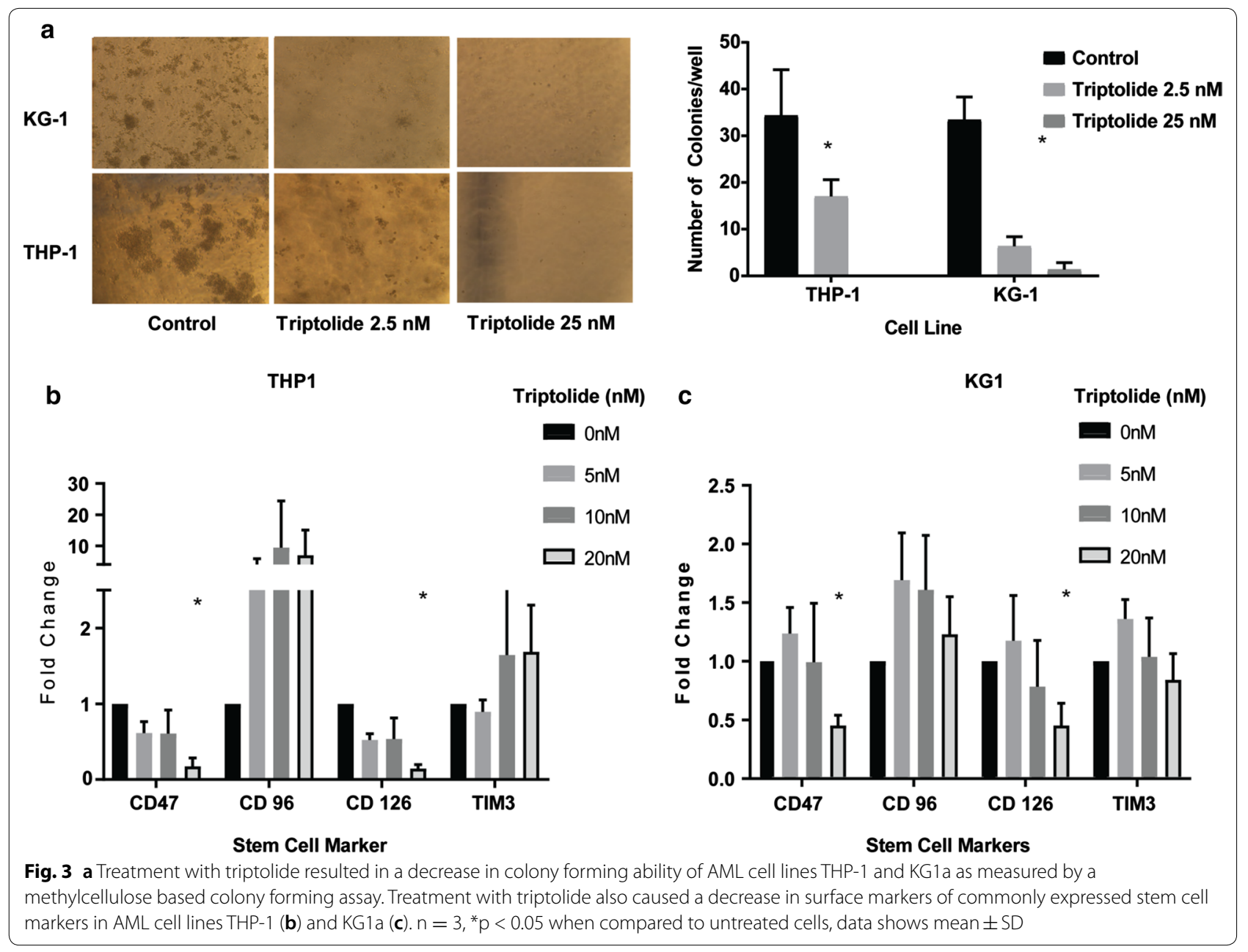

The original article can be found online at https://doi.org/10.1186/s1296 Publisher's Note 7-019-1901-8

Springer Nature remains neutral with regard to jurisdictional claims in published maps and institutional affiliations.

Published online: 04 September 2019

\section{Reference}

1. Giri B, Gupta VK, Yaffe B, Modi S, Roy P, Sethi V, Lavania SP, Vickers SM, Dudeja V, Banerjee S, Watts J, Saluja A. Pre-clinical evaluation of Minnelide as a therapy for acute myeloid leukemia. J Transl Med. 2019;17:163. https ://doi.org/10.1186/s12967-019-1901-8. 